\title{
Computed Tomography Imaging of Degenerative Disease in the Lumbar Spine
}

\author{
V. A. Malakhanov, $\mathrm{PhD}^{1,2,3}$; P. V. Seliverstov, $\mathrm{PhD}, \mathrm{ScD}^{1 *}$; Ya. A. Lubashev, $\mathrm{PhD}, \mathrm{ScD}^{4}$; \\ V. A. Ratnikov, $\mathrm{PhD}, \mathrm{ScD}^{5}$ \\ ${ }^{I}$ Irkutsk Scientific Center of Surgery and Traumatology, Russia \\ ${ }^{2}$ Irkutsk Municipal Clinical Hospital №1, Russia \\ ${ }^{3}$ Road Clinical Hospital at Irkutsk-Passenger Station of JSCo "RZD”, Russia \\ ${ }^{4}$ Branch Clinical Diagnostic Center of PJSC Gazprom, Moscow, Russia \\ ${ }^{5}$ Clinical Hospital № 122 named after L.G. Sokolov under the Federal Biomedical Agency of the Russian \\ Federation, St. Petersburg, Russia
}

\begin{abstract}
The degenerative spinal lesions are one of the most frequent causes of lumbar pain syndrome. Diagnosing them is difficult due to poor correlation between radiological data and clinical symptoms. Computed tomography is one of the key modalities in the diagnosis of degenerative disc disease. (International Journal of Biomedicine. 2019;9(2):182-184.)
\end{abstract}

Key Words: lumbar spine $\bullet$ degenerative spine $\bullet$ computed tomography $\bullet$ lumbar stenosis.

\section{Introduction}

Osteochondrosis is the most commonly encountered form of degenerative spinal lesion with a primary degeneration of nucleus pulposus as a base. Hyaline plates and adjacent areas of vertebral bodies become injured because of lack of nucleus pulposus elasticity, which leads to fissures and ruptures of the hyaline lamellae (Schmorl's nodes) and the annulus fibrosus (disc protrusions and herniations). Other components of the spinal motion segment (vertebral bodies, ligaments, articulations) eventually get involved in this pathological process, and then osteosclerosis develops in adjacent bone parts and the body height decreases. The articular surfaces become displaced, so the subluxation in facet joints gradually appears, and osteoarthrosis develops. ${ }^{(1,2)}$

Degenerative changes finally lead to spinal stenosis with pain syndrome in its debut. There are central and lateral

*Corresponding author: Pavel V. Seliverstov, MD. Irkutsk Scientific Center of Surgery and Traumatology. Irkutsk, Russia. E-mail: pavv2001@gmail.com (foraminal) forms of spinal stenosis: relative - over $12 \mathrm{~mm}$ and absolute - under $12 \mathrm{~mm}$. Many researchers describe the incompatibility between the imaging and clinical signs. In cases of relative stenosis there are no clinical findings, but minimal intervertebral protrusion could produce significant pain with myelopathy. ${ }^{(3)}$

Spinal computed tomography (CT) can provide assessment of details of the configuration of the bone canal's walls; can prove the fact of presence of disc herniation; and can define its dimensions, the diameter of vertebral and foraminal canals. ${ }^{(4)}$ The cause of the lumbar canal's stenosis in most patients with degenerative spinal disease is the segmental degenerative instability related to intervertebral destruction. ${ }^{(5)}$

\section{Materials and Methods}

Fifty patients had lumbar spine CT (Toshiba Aquilion One 64) studies at the Radiology Department of Road Clinical Hospital in the period from August 2018 to February 2019. All patients (mean age of $48 \pm 12.0$ years), predominantly ablebodied men between 40 and 59 years of age, had chronic lumbar pain and neurogenic intermittent claudication. 


\section{Results and Discussion}

All 50 patients with neurological symptoms of osteochondrosis had degenerative spinal CT changes (Table 1).

\section{Table 1.}

CT signs of osteochondrosis in the lumbar spine

\begin{tabular}{|l|c|c|}
\hline \multirow{2}{*}{\multicolumn{1}{|c|}{ Pathological process }} & \multicolumn{2}{c|}{ Patients } \\
\cline { 2 - 3 } & $\mathrm{n}$ & $\%$ \\
\hline Spondylosis & 38 & 76 \\
\hline Spondyloarthrosis & 33 & 66 \\
\hline Dystrophic stenosis of vertebral canal & 4 & 8 \\
\hline Spondylolisthesis & 3 & 6 \\
\hline Osteophyte in vertebral canal & 5 & 10 \\
\hline Hypertrophy of facet joint & 3 & 6 \\
\hline
\end{tabular}

CT showed a decrease in the intervertebral disc height, a vacuum phenomenon, a disc protrusion, a lordosis alignment, a vertebral displacement (Fig.1), an ossification of posterior longitudinal ligament (Fig.2), and a subchondral osteosclerosis.

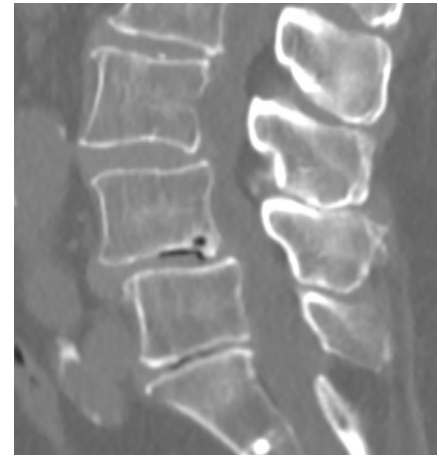

Fig. 1. CT, sagittal view.

Spondylolisthesis at the L3-L4 level, Ossification of posterior longitudinal grade 1.

The Schmorl's nodes were visualized in $75 \%$ of patients as an intracorporal intrusion of discs with a hyperdense rim. Osteoarthrosis often induces a decrease of lateral recess (average diameter $>5 \mathrm{~mm}$ ). Further progression of degenerative process leads to load increase to facet joints with their deformation. The main radiological signs of spondyloarthrosis were a decrease of the articular space height, subchondral epiphyseal osteosclerosis, formation of osteophytes, the vacuum phenomenon and subchondral cysts (Fig.3).

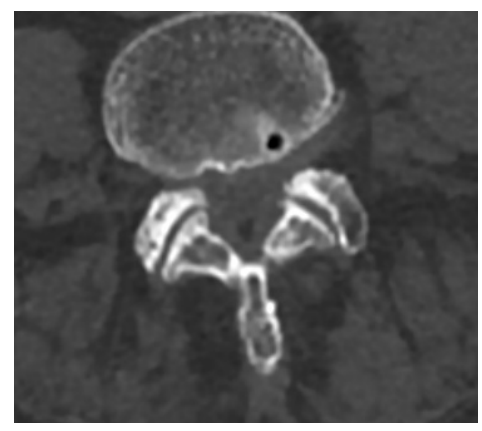

Fig. 3. CT, axial view. Facet joints arthrosis.
The herniation level was assessed on the axial and sagittal views; we took such a horizontal disc deformation when the diameter of herniation exceeded its width because CT could not show the continuity of the annulus fibrosus under the herniated disc. The dimensions and the localization of disc herniations are demonstrated (Table 2).

Table 2.

A frequency of different forms of disc herniations in the lumbar spine

\begin{tabular}{|l|c|c|}
\hline \multirow{2}{*}{\multicolumn{1}{|c|}{ The forms of disc herniations }} & \multicolumn{2}{c|}{ Number $(\mathrm{n}=20)$} \\
\cline { 2 - 3 } & $\mathrm{n}$ & $\%$ \\
\hline Median & 3 & 15 \\
\hline Paramedian & 7 & 35 \\
\hline Posterolateral & 4 & 20 \\
\hline Foraminal & 3 & 15 \\
\hline Sequestrated & 3 & 15 \\
\hline
\end{tabular}

The disc herniations were visualized in 20(40\%) patients, $4(8 \%)$ of them had 2 herniated discs (Fig.4). The majority of disc herniations were between $5 \mathrm{~mm}$ and $8 \mathrm{~mm}$ in size $(75.5 \%)$, of paramedian form (35\%), and occurred at L4 L5 and L5-S1 levels (Fig.5). There were sequestrated discs in $3(15 \%)$ patients.
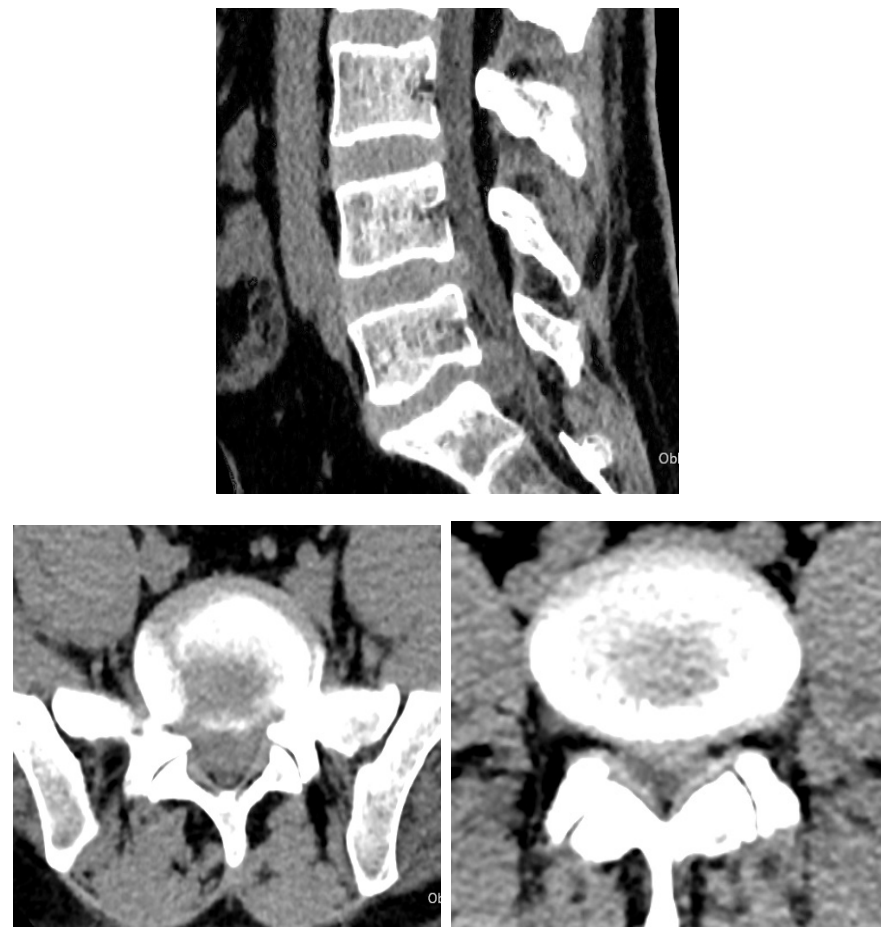

Fig. 4. CT, sagittal and axial views. The disc herniations at L4-L5, L5-S1, spondylolisthesis L5.

CT showed stenosis of the spinal canal in 19(38\%) patients, $15-18 \mathrm{~mm}$ in its sagittal diameter. The causes of spinal stenosis were the posterior and posterolateral osteophytes, spondylarthrosis, spondylolisthesis, ossification of posterior longitudinal ligaments, and hypertrophy of ligamentum flavum $(>5 \mathrm{~mm})$. 


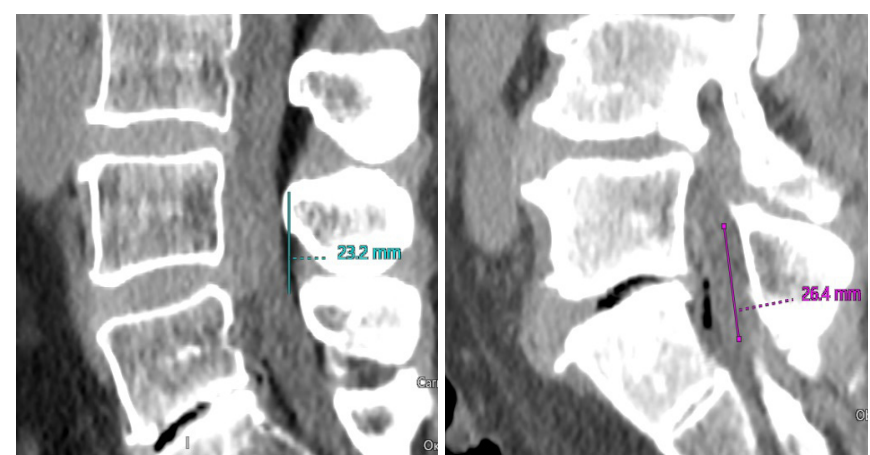

Fig. 5. CT, sagittal view. The sequestrated disc herniations.

\section{Conclusion}

Thus, degenerative spinal lesions are one of the most frequent causes of lumbar pain syndrome. Diagnosing them is difficult due to poor correlation between radiological data and clinical symptoms. CT is one of the key modalities in the diagnosis of degenerative disc disease; it permits us to visualize the signs of spinal stenosis. Therefore, CT should be performed on patients with chronic lumbar pain and neurogenic intermittent claudication.

\section{Competing Interests}

The authors declare that they have no competing interests.

\section{References}

1. Boos N, Aebi M. Spinal Disorders Fundamentals of Diagnosis and Treatment. Berlin: Springer Verlag; 2008. doi: 10.1007/978-3-540-69091-7.

2. Kapural L, Kim P, Deer T. Diagnosis, Management, and Treatment of Discogenic Pain. NY; Philadelphia: Elsevier Science; 2011.

3. NouriA, TetreaultL, SinghA, Karadimas SK, Fehlings MG. Degenerative Cervical Myelopathy: Epidemiology, Genetics, and Pathogenesis. Spine (Phila Pa 1976). 2015;40(12):E67593. doi: 10.1097/BRS.0000000000000913.

4. Van Goethem JWM, Hauwe L, Parizel PM. Spinal imaging. Diagnostic imaging of the Spine and Spinal Cord. Springer-Verlag, Berlin-Heidelberg; New York; 2007.

5. Hayashi T, Wang JC, Suzuki A. Takahashi S, Scott TP, Phan K, et al. Risk factors for missed dynamic canal stenosis in the cervical spine. Spine (Phila Pa 1976). 2014 ;39(10):8129. doi: 10.1097/BRS.0000000000000289. 